\title{
Article
}

\section{On-Line Control of Stresses in the Power Unit Pressure Elements Taking Account of Variable Heat Transfer Conditions}

\author{
Andrzej Rusin*D, Martyna Tomala, Henryk Łukowicz, Grzegorz Nowak and Wojciech Kosman \\ Department of Power Engineering and Turbomachinery, Silesian University of Technology, \\ 44-100 Gliwice, Poland; martyna.tomala@polsl.pl (M.T.); henryk.lukowicz@polsl.pl (H.Ł.); \\ grzegorz.nowak@polsl.pl (G.N.); wojciech.kosman@polsl.pl (W.K.) \\ * Correspondence: andrzej.rusin@polsl.pl
}

Citation: Rusin, A.; Tomala, M.; Łukowicz, H.; Nowak, G.; Kosman, W. On-Line Control of Stresses in the Power Unit Pressure Elements Taking Account of Variable Heat Transfer Conditions. Energies 2021, 14, 4708. https://doi.org/10.3390/en14154708

Academic Editor: Bruno Facchini

Received: 2 July 2021

Accepted: 29 July 2021

Published: 3 August 2021

Publisher's Note: MDPI stays neutral with regard to jurisdictional claims in published maps and institutional affiliations.

Copyright: (c) 2021 by the authors. Licensee MDPI, Basel, Switzerland. This article is an open access article distributed under the terms and conditions of the Creative Commons Attribution (CC BY) license (https:// creativecommons.org/licenses/by/ $4.0 /)$.
Abstract: Coal-fired power units, now balancing power shortages in the power system, must be characterised by increasingly higher flexibility of operation. This means faster start-ups and the capacity for frequent decreases and increases in the power output. These processes cause large temperature gradients in elements of the power unit and the turbine and lead to an increase in the stress level. At such an operating regime it is impossible to ensure safety based on start-up characteristics only-it becomes necessary to constantly monitor stress levels in critical areas of machinery and equipment elements. The stress level in turbine elements can be monitored on-line using algorithms based on Green's functions and Duhamel's integral. This paper presents examples of modifications of stress calculations in turbine valves and casings during start-ups. By modifying basic algorithms, it is possible to take into account the impact of the variability of heat transfer coefficients on the thermal stress level. Additionally, individual Green's functions and correction factors were determined for specific stages of start-ups. Due to modifications, it is possible to obtain satisfactory agreement with the results obtained from FEM-based calculations for the entire heating process. Equations are also given that enable estimation of values of the heat transfer coefficient in turbine valves. The proposed modification of the algorithm will substantially improve the accuracy of stress modelling in transient states of the turbine operation. On-line stress monitoring will enable an increase in the flexibility of the power unit operation and facilitate operational control, ensuring safety of individual elements at the same time. The stress values calculated in the on-line mode can also be used to estimate fatigue life consumption and forecast the residual lifetime of individual components.

Keywords: thermal stresses; Green's functions; on-line monitoring; heat transfer coefficients

\section{Introduction}

Power unit start-ups carried out according to the manufacturer's recommendations should ensure operating safety. Steam turbines are started based on start-up characteristics showing the recommended rate of increments in relevant parameters, such as temperature, pressure and mass flow of steam, the rotor rotational speed, and the power output. However, real measured values of the parameters may differ from those set out in the recommendations. Moreover, coal-fired power units, which are now used to balance power shortages in the power system, are required to demonstrate increasingly higher flexibility of operation. This means faster start-ups and more frequent increases and decreases in the power output [1-3]. Due to that, large temperature gradients arise in elements of the power unit and of the turbine, and this creates a higher risk of a serious failure [4]. At such an operating regime it is impossible to ensure safety based on start-up characteristics only-it becomes necessary to constantly monitor stress levels in critical areas of machinery and equipment elements. On-line stress control enables safe acceleration of start-ups and improvement in the dynamics of the power unit operation. It also makes it possible to assess the life consumption and forecast the residual lifetime of elements of power plants. 
The biggest challenge in the development of the method of on-line control of the material stress-and-strain state is the way of determining thermal stresses. The response of the element material to thermal stresses is more complex compared to loads caused by steam pressure or the mass load due to the rotation of rotors. Many algorithms were developed for the calculation of thermal stresses in boiler and turbine elements based on on-line measurements of parameters carried out in power plants [5]. They were then used to optimise the start-up process. Examples of such analyses are presented, among others, in [6,7] for elements of the boiler and in [8,9] for elements of the turbine. The way of using on-line stress monitoring systems to calculate the fatigue life of the material of turbine rotors is presented in [10] and an on-line fatigue-creep monitoring system for high-temperature components of power plants is discussed in [11].

This article discusses the stress monitoring methods based on Green's functions and the proposed modification of the basic algorithm (Section 2). The new method allows to take into account the variability of the heat transfer coefficient during start-up, therefore the method of determining the value of this coefficient on the surface of the turbine valve is presented in Section 3. The calculated values of stresses were compared with the values obtained by means of FEM for two components: the valve and the turbine inner casing. Start-ups from different thermal states are considered (Section 4). In Section 5 the proposed of the use of an online stress monitoring system to control turbine operation is described. The performed research is summarised in Section 6.

\section{Algorithms for Stress Calculation in Turbine Elements}

\subsection{Agorithms Based on Green's Functions}

The simplest algorithms mapping maximum stresses $\sigma_{\text {max }}$ arising in characteristic points of elements are based on the measurement of temperature differences $\Delta T$ or temperature derivatives $d T_{m} / d T$ in the element:

$$
\begin{gathered}
\sigma_{\max }=f(\Delta T) \\
\sigma_{\max }=f\left(\frac{d T_{m}}{d t}\right)
\end{gathered}
$$

More advanced algorithms make use of the so-called influence functions illustrating the stress-related response of the material to the unit step function in the form of a jump in temperature. Total stress is calculated using the superposition method, i.e., summing unit responses (cf. Figure 1).

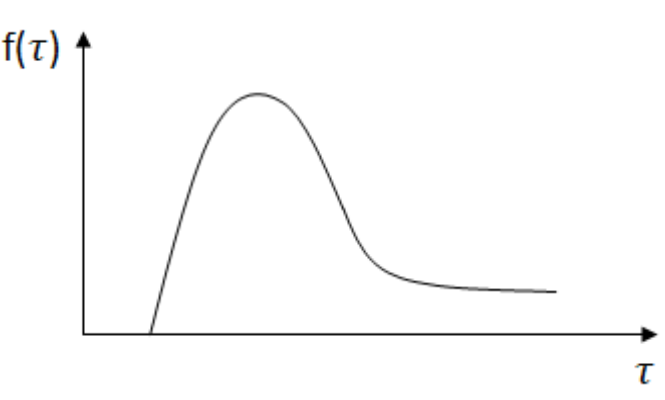

(a)

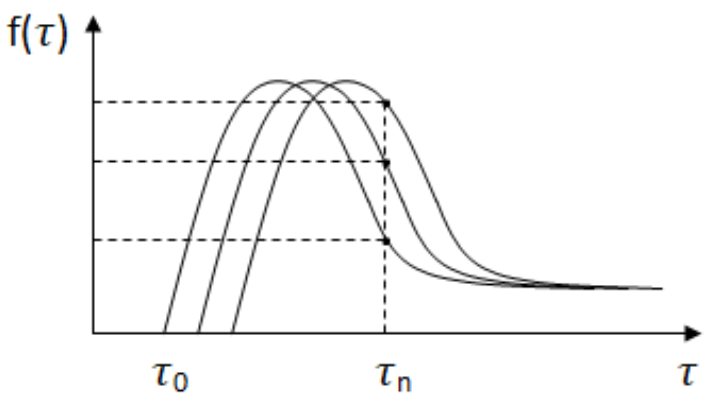

(b)

Figure 1. (a) Influence function; (b) superposition method.

Green's function $f_{G}(t)$ is used as the influence function $T(\tau)$ describing the material stress-related response to a change in the temperature of the fluid flowing around the 
element, whereas individual components of thermal stress $\sigma^{T}$ in a given time instant are calculated using Duhamel's integral:

$$
\sigma^{T}=\int_{0}^{t} \frac{d T(\tau)}{d \tau} f_{G}(t-\tau) d \tau
$$

So-developed algorithms make it possible to map real-time changes in stresses. One downside of the solution is that it does not take account of changes in the material properties resulting from variations in the operating temperature; nor does it take account of changes in the coefficients of the heat transfer between steam and the surface of individual elements.

To reduce the divergences between the calculated and the real stress level, the abovementioned algorithm is modified. Paper [12] presents a method of determining stresses in the rotor of a supercritical turbine high-pressure part. Instead of using the temperature of steam flowing through the element, the method uses the direct temperature of the metal, which can be determined by means of the finite element or the finite difference method. Paper [13] presents an alternative method using neural networks to determine stresses in turbine elements.

Paper [14] describes the way of introducing temperature-dependent variations in material properties into the algorithm. The process of the element heating is divided into a few stages for which separate Green's functions are determined taking account of the material properties in a given temperature. A neural network is then used. The network is subjected to a self-teaching process based on determined influence functions. The new Green's functions are modified through an introduction of a weight coefficient. The coefficient ensures limitation of the divergences between stresses obtained by means of the described method and those found using the FEM. The way of taking account of the temperature-dependent variability of steel properties is also discussed in $[15,16]$.

A modification of the Green's function-based method that makes it possible to take account of the variability of the heat transfer coefficient in the calculations is presented in [17]. The change in steam temperature $T(\tau)$ in Equation (3) is replaced with a modified temperature calculated as:

$$
T_{\text {mod }}=\frac{\alpha(\tau) \cdot\left(T(\tau)-T_{m}(\tau)\right)}{\alpha_{\text {mod }}}+T_{m}(\tau)
$$

where $\alpha(\tau)$-is the heat transfer coefficient at a given time instant, $T_{m}(\tau)$-is the metal temperature at a given time instant, and $\alpha_{\text {mod }}$-is the heat transfer coefficient for which the Green's function was determined.

\subsection{Modification of the Algorith for Thermal Stress Determination}

The steam turbine start-up involves an intense and variable heat exchange over time between the surface of the turbine components and the steam flowing through them. This produces a very wide range of changes in the heat transfer coefficient values. They vary from a few to a few thousand $\mathrm{W} / \mathrm{m}^{2} \mathrm{~K}$ depending on the monitored area. In the case of such big differences, the basic stress calculation algorithm using Green's functions and Duhamel's integral proves insufficient. A need therefore arises to modify the method. The start-up period is divided into stages defined using intervals of the heat transfer coefficient values that change during the process. For each interval, an individual constant or in-time-varying correction factor $k$ is introduced to minimise the difference between the results obtained using Green's functions and those considered to be closest to reality and calculated using the finite element method. The factor is used to determine the modified temperature of steam based on Equation (4) modified as follows:

$$
T_{\text {mod }}=\frac{\alpha(\tau) \cdot\left(T(\tau)-T_{m}(\tau)\right)}{k}+T_{m}(\tau)
$$


The obstacle to the method application is the determination of the time-dependent temperature of metal in the monitored area. Unlike steam parameters, this temperature is not controlled by the measuring systems. To estimate the temperature at any moment of the start-up process, influence functions $f_{T_{n}}(\tau)$ are determined. The functions can be defined using the finite element method and are assigned to specific intervals of the heat transfer coefficient values. The metal temperature is then found using the following equation [10]:

$$
T_{m}=\int_{0}^{t} \frac{d T(\tau)}{d \tau} f_{T_{n}}(t-\tau)
$$

Like in the case of influence function $f_{T_{n}}(\tau)$, Green's functions $\left(f_{n}\right)$ are assigned to each interval of the heat transfer coefficient. The thermal stress components are determined from the following relation:

$$
\sigma^{T}=\int_{0}^{t} \frac{d T_{m o d}(\tau)}{d \tau} f_{G_{n}}(t-\tau) d \tau
$$

The complete algorithm of actions needed to determine thermal stresses is presented in Figure 2.

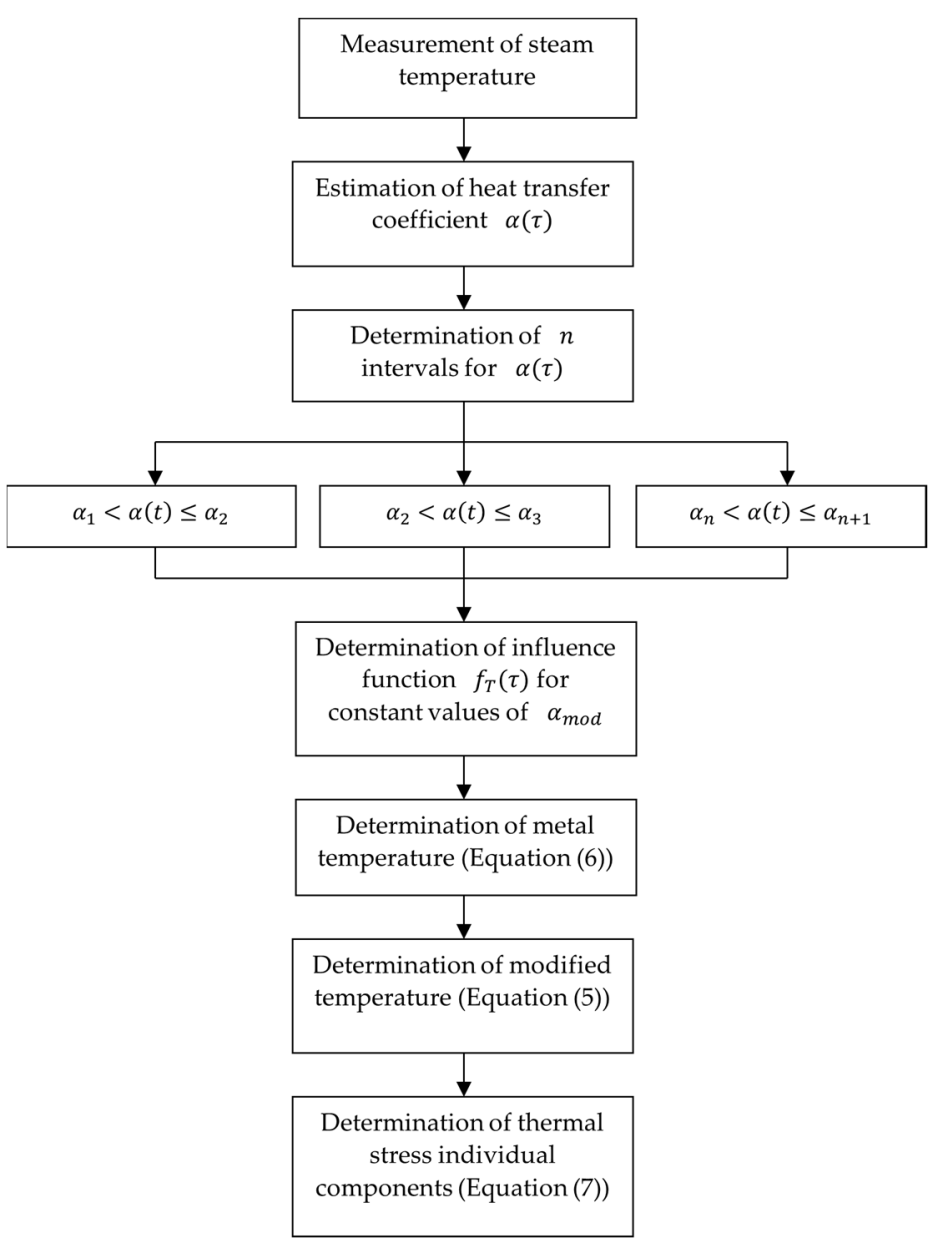

Figure 2. Algorithm for thermal stress calculation.

\section{Determination of Heat Transfer Coefficients}

The essence of the proposed modification of the algorithms for thermal stress calculation is to make them take account of the heat transfer coefficient variability between steam 
and the surface of the heated elements. This change in the heat transfer conditions has an impact on the temperature gradients arising in the elements and thereby affects the thermal stress level. Heat transfer coefficients are defined on the surface of the main elements, i.e., valves, casings, shafts, blade grooves, rotor labyrinth seals, etc.

The values of the heat transfer coefficient for these surfaces are determined using the following general form [18]:

$$
N u=C R e^{m} \operatorname{Pr}^{n}
$$

where $\mathrm{Nu}$-Nusselt number, Re-Reynolds number, $\mathrm{Pr}$-Prandtl number.

Exemplary equations for the heat transfer coefficient calculations developed based on the literature data and using the results of our own studies are discussed, among others, in [19-21]. The phenomena of heat and mass transfer show analogies, so the problem of determining the heat transfer coefficients can be reduced to the determination of the average and local mass transfer coefficient using the Chilton Colburn analogy. The method described in detail, among others in $[20,21]$, was used to determine the heat transfer coefficients in turbine valves using sublimation of naphthalene in air for mass transfer modelling. A detailed description of the measurements, the measurement stand, the results, and their discussion are presented in [20].

Based on the results from [20], the heat transfer coefficient distribution in a model turbine valve (cf. Figure 3) was determined and general equations were developed for each of the areas marked in Figure 3:

$$
N u=C R e^{0,8}
$$

where:

$$
N u=\frac{\alpha d_{k}}{\lambda_{p}}, R e=\frac{w d_{k}}{v_{p}}
$$

where $d_{k}$-diameter of the valve inlet connector pipe.

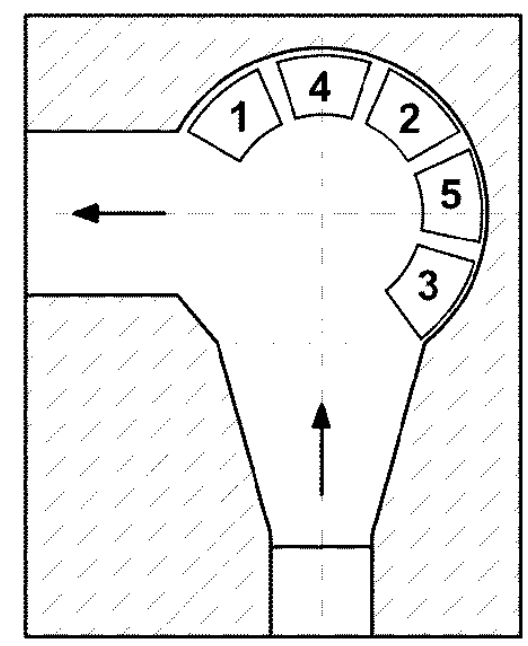

Figure 3. Model of the valve, 1, 2, 3, 4, 5-areas of coefficient measurement.

Based on the results obtained from experimental testing, the values of coefficient $C$ were estimated using Equation (9). Exemplary equations for the calculation of the areas schematically shown in Figure 3 have the following form:

$$
\begin{aligned}
& N u_{1}=0.066 R e^{0,8} \\
& N u_{2}=0.069 R e^{0,8} \\
& N u_{4}=0.055 R e^{0,8}
\end{aligned}
$$


A correlation function similar to (9) was also determined, which defines the mean value of the Nusselt number $(\mathrm{Nu})$ for the whole valve chamber.

$$
N u=0.06315 R e^{0,8}
$$

The above equations for the calculation of the heat transfer coefficient were used to modify the algorithm for calculating the stresses in the pressure components of the turbine.

\section{Application of the Proposed Algorithm for Stress Calculation in Turbine Pressure Components}

\subsection{Turbine Inner Casing}

The proposed calculation scheme was used to monitor stresses in selected pressure components of a $200 \mathrm{MW}$ steam turbine. The finite element method using the ANSYS software was applied to identify critical areas that should be covered by the stress monitoring. The tetrahedral mesh type with 72,176 elements was selected. The analysis was conducted in two stages. Initially, the calculations of the temperature distribution in the component were carried out, where the boundary conditions were the fluid temperature and heat transfer coefficient. The structural analysis was then performed with the fluid pressure as an additional boundary condition. Effective stresses distribution in the turbine inner casing during a start-up from the cold state carried out according to the steam parameters shown in Figure 4 is presented in Figure 5.

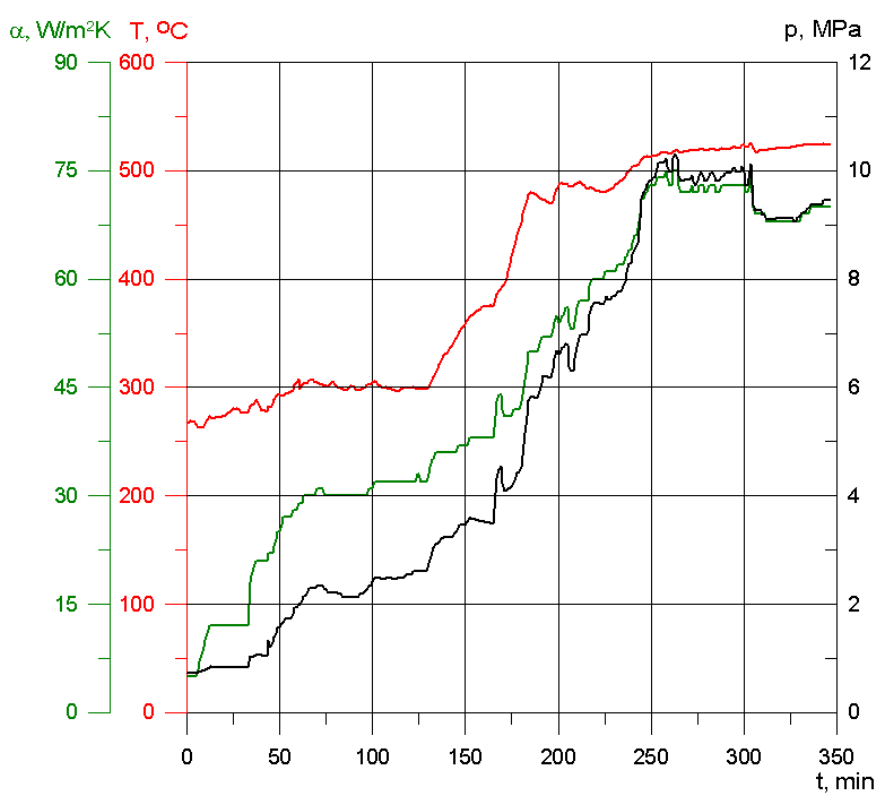

Figure 4. Change in steam parameters during turbine cold start-up (data for turbine inner casing), $\alpha$-heat transfer coefficient, $T$-steam temperature, $p$-steam pressure. 


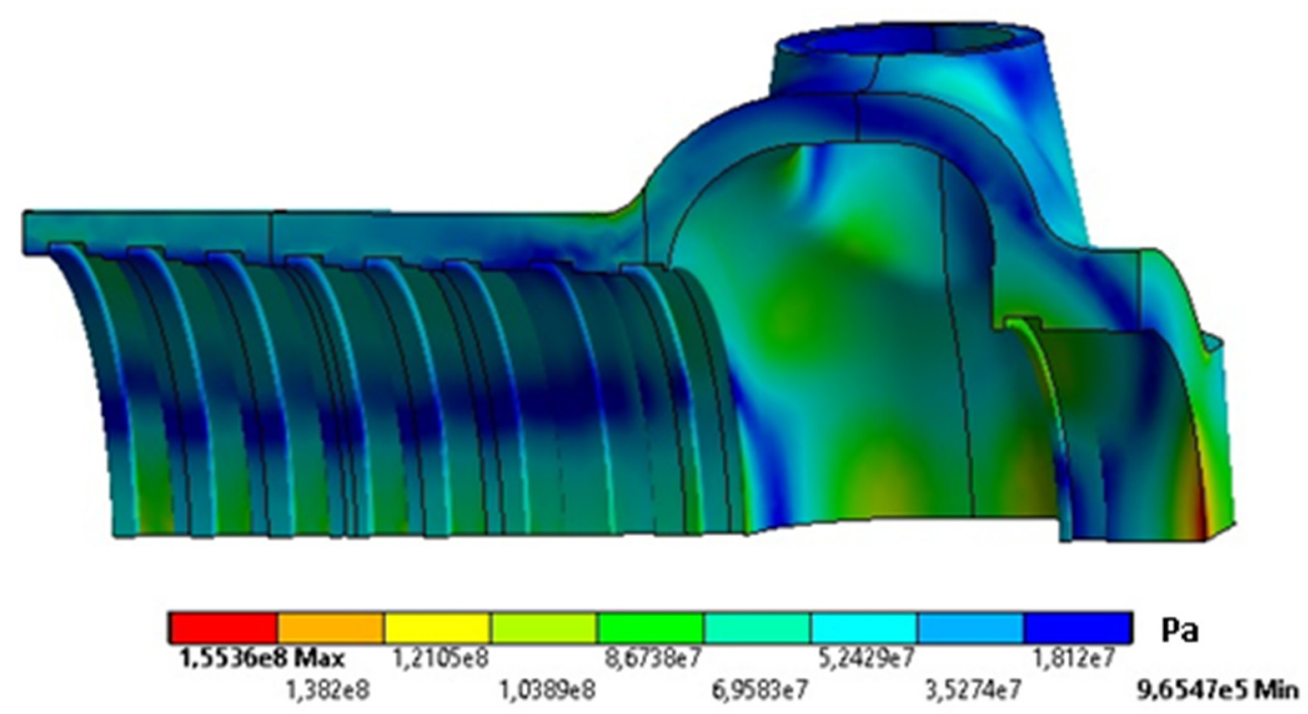

Figure 5. Distribution of effective stresses in turbine inner casing during the cold start-up.

The monitored point (cf. Figure 6) is situated on the inner surface of the casing in the steam inlet area. This area is characterised by high values of stresses and also by high temperatures of metal, which intensifies the creep-related life consumption process.

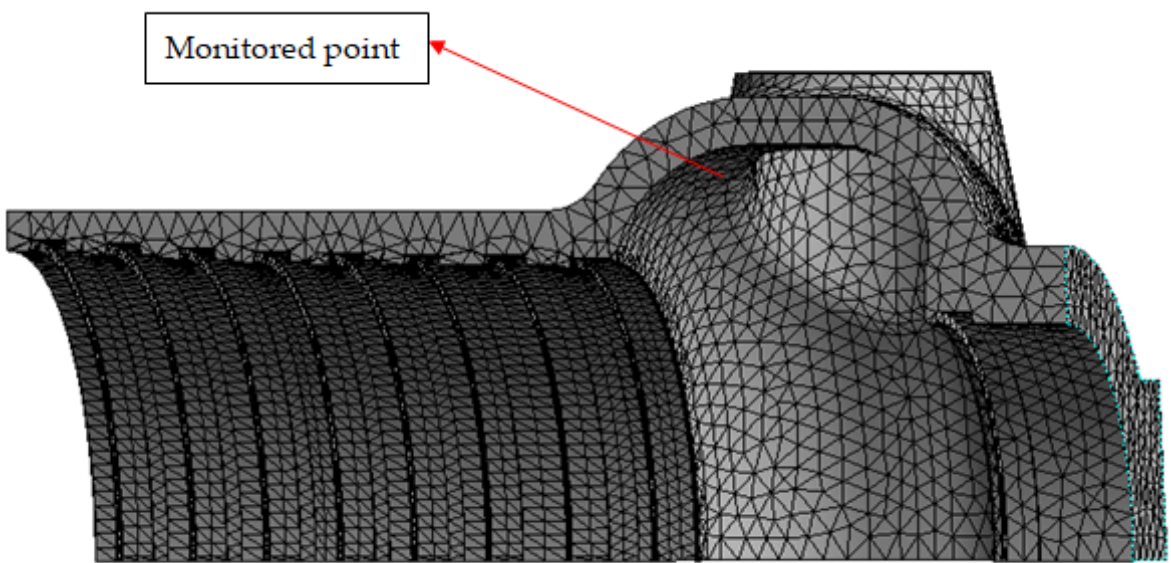

Figure 6. Point monitored in the turbine inner casing.

The turbine start-up from the cold state can be carried out with or without feeding heating steam into the inter-casing space. This means that, depending on the start-up type, higher or lower heat transfer coefficients occur on the casing outer surfaces. Due to this difference, the influence functions, both for the metal temperature and for the arising stresses, have to be developed for both variants of the start-up.

Considering the relatively small range of variation of the heat transfer coefficient in the area monitored during the start-up $\left(\Delta \alpha \approx 70 \mathrm{~W} / \mathrm{m}^{2} \mathrm{~K}\right)$, only one interval $(n=1)$ was adopted, according to Figure 2, and influence functions were determined showing the change in the metal temperature due to a unit increase in the temperature of steam washing the element. Influence functions were determined for $\alpha_{\text {modI }}=23 \mathrm{~W} / \mathrm{m}^{2} \mathrm{~K}$ and $\alpha_{\text {modII }}=37 \mathrm{~W} / \mathrm{m}^{2} \mathrm{~K}$, respectively, for the variant with and without heating in the intercasing space, based on FEM calculations (cf. Figure 7). 


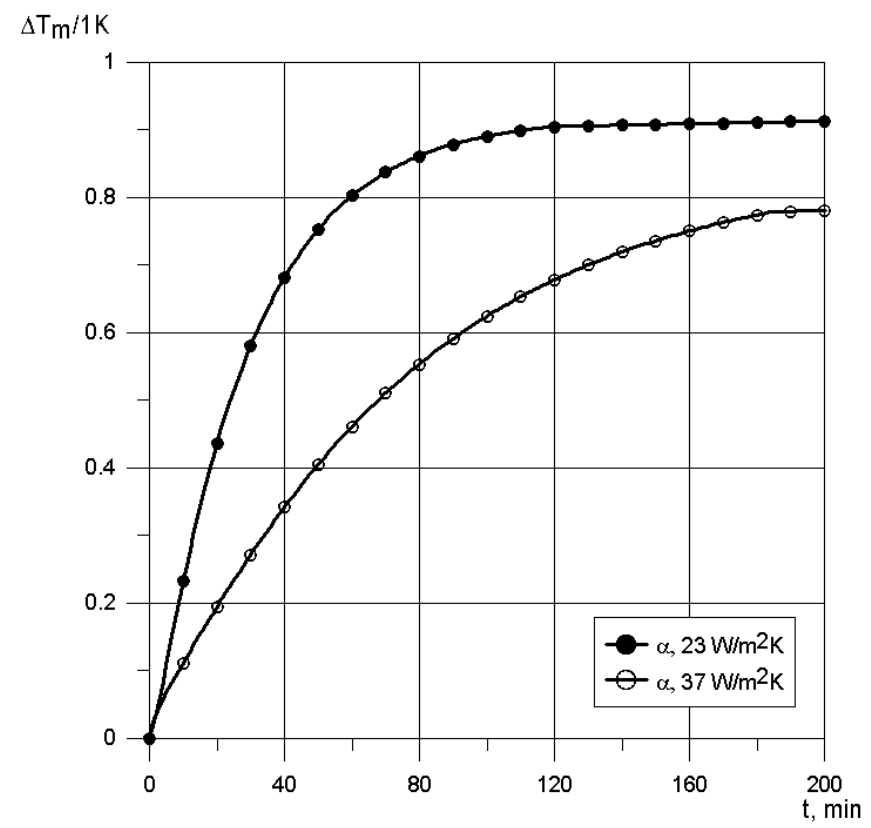

Figure 7. Influence function for the metal temperature in the inner casing (start-up with and without heating).

The FEM was also used next to determine Green's functions for individual stress components at a constant heat transfer coefficient value of $\alpha_{\bmod I}=23 \mathrm{~W} / \mathrm{m}^{2} \mathrm{~K}$ (variant with heating) and $\alpha_{\text {modII }}=37 \mathrm{~W} / \mathrm{m}^{2} \mathrm{~K}$ (variant without heating). Figures 8 and 9 present the obtained relations for the normal and the tangential stress component, respectively.

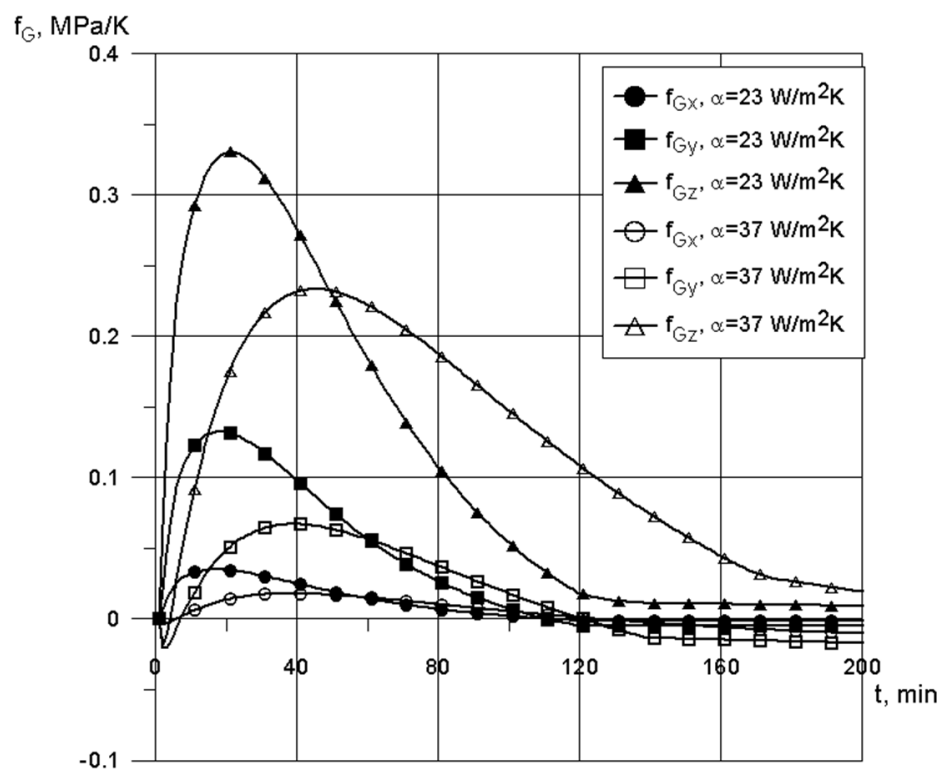

Figure 8. Green's functions for the stress normal components in the inner casing (start-up with and without heating). 


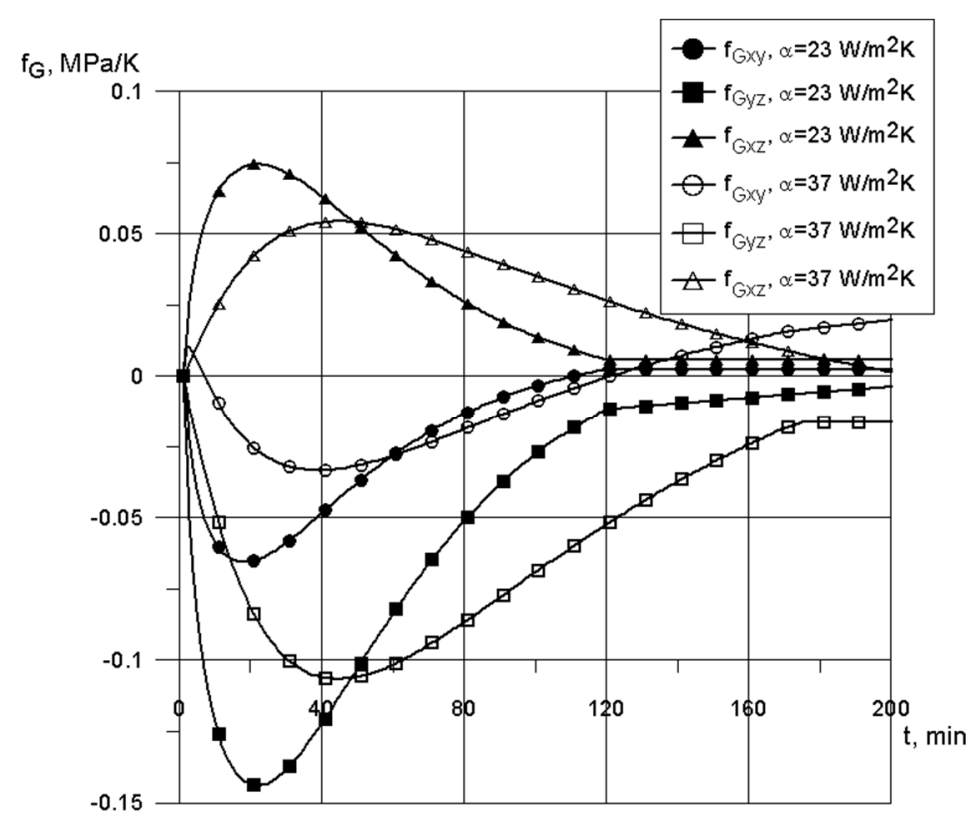

Figure 9. Green's functions for the stress tangential components in the inner casing (start-up with and without heating).

Based on the comparison of thermal stresses obtained using the finite element method and the algorithm using Green's functions, variable correction factors were selected: $k(t)=0,9 \cdot \alpha(t)$ (variant with heating) and $k(t)=\alpha(t)$ (variant without heating). The factors were selected based on an analysis of a few kinds of start-ups.

The turbine inner casing is a pressure component and therefore it is necessary to determine stresses being an effect of loads due to steam pressure. The correlation between pressure and the stress it produces can be written as follows:

$$
\sigma^{p}=a \cdot p+b
$$

where $a, b$-coefficients determined individually for each stress component, $p$-steam pressure.

The following relations were determined for the monitored area of the casing (the coefficients were calculated for the pressure given in $\mathrm{MPa}$ ):

$$
\begin{gathered}
a_{x}=-0.904, b_{x}=0 \\
a_{y}=-0.772, b_{y}=0 \\
a_{z}=1.462, b_{z}=-0.925 \\
a_{x y}=-0.904, b_{x y}=0 \\
a_{y z}=-1.141, b_{y z}=0 \\
a_{x z}=0.629, b_{x z}=0
\end{gathered}
$$

Individual components of thermal and mechanical stresses arising due to the impact of steam pressure are summed, and effective stress is determined next:

$$
\sigma_{\text {red }}=\sqrt{\sigma_{X}^{2}+\sigma_{Y}^{2}+\sigma_{Z}^{2}-\sigma_{X} \sigma_{Y}-\sigma_{Y} \sigma_{Z}-\sigma_{X} \sigma_{Z}+3\left(\tau_{X Y}^{2}+\tau_{Y Z}^{2}+\tau_{X Z}^{2}\right)}
$$

The results of the effective stress calculations were compared to the values obtained using the finite element method. The analysis was conducted for start-ups from three different thermal states. Figure 10 presents curves illustrating changes in stresses in the monitored point of the casing during a cold start-up carried out according to the change in steam parameters shown in Figure 4. The start-up from the cold state is carried out with steam fed into the inter-case space. 


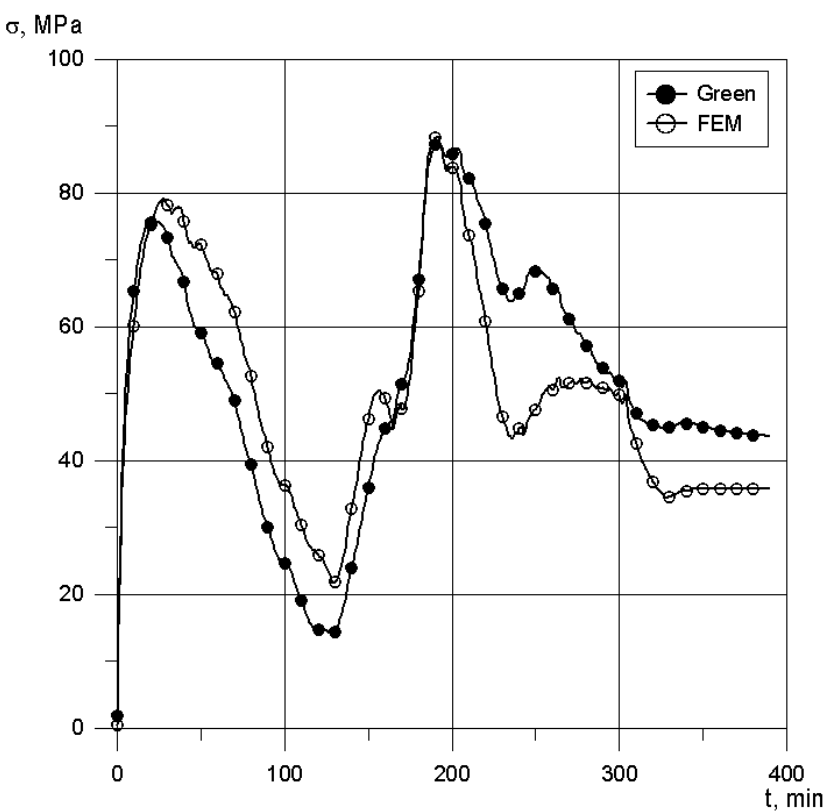

Figure 10. History of changes in stresses in the turbine inner casing during the cold start-up.

The warm start-up was carried out according to the change in steam parameters shown in Figure 11, with no additional heating of the inter-casing space. The results obtained from the modified method using Green's functions and from the FEM are compared in Figure 12.

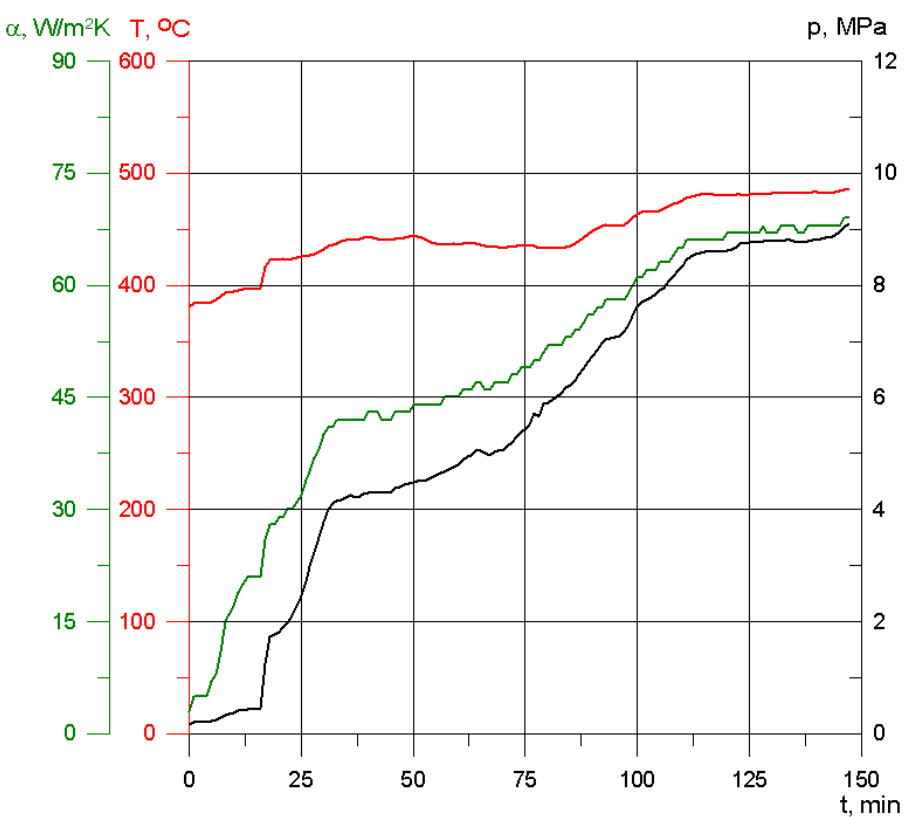

Figure 11. Increment in steam parameters during the warm start-up (data for turbine inner casing), $\alpha$-heat transfer coefficient, $T$-steam temperature, $p$-steam pressure. 


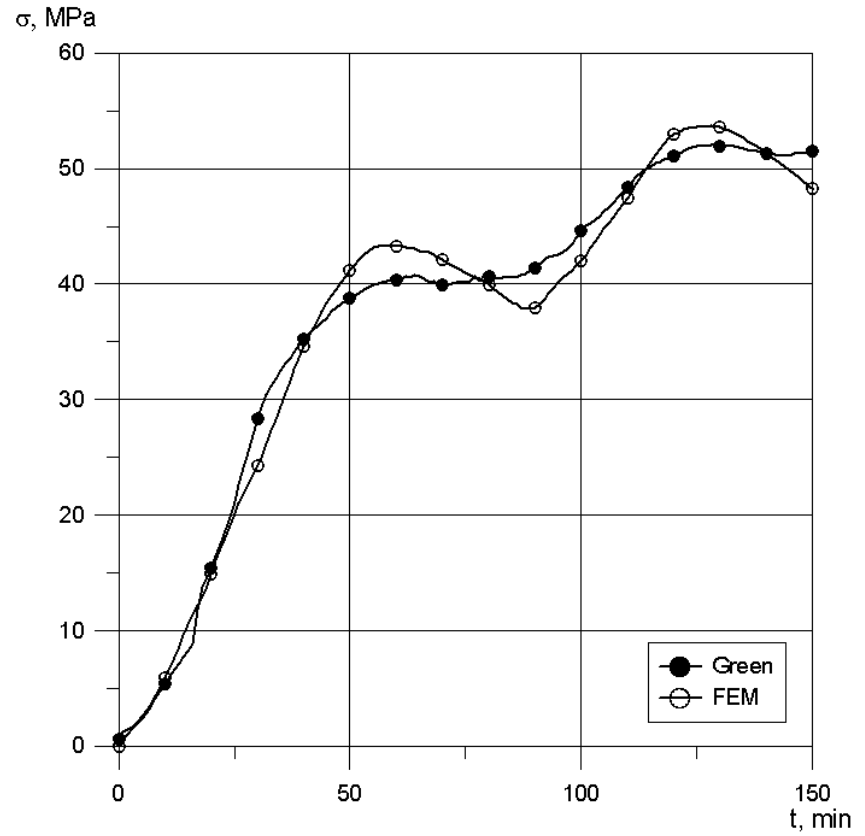

Figure 12. History of changes in stresses in the inner casing during the warm start-up.

The last variant under analysis was the start-up from the hot state, which is also carried out without feeding heating steam into the inter-casing space. It is characterised by the highest temperature of steam fed at the beginning of the process, which can be seen in Figure 13. The history of changes in effective stresses for the monitored point of the casing is presented in Figure 14.

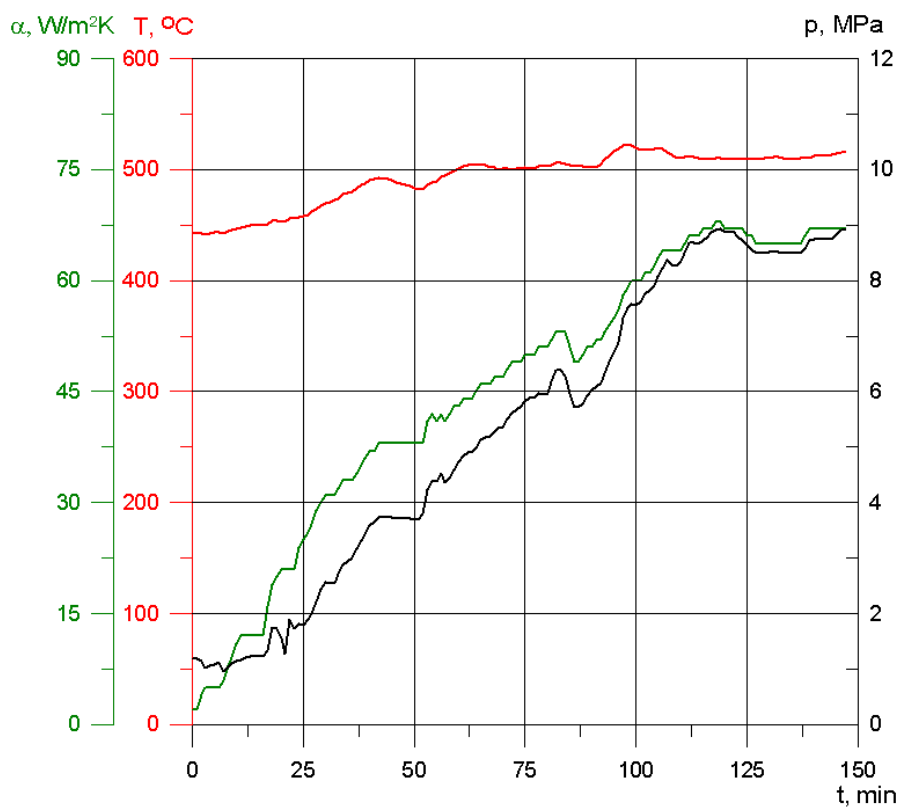

Figure 13. Change in steam parameters during the hot start-up (data for turbine inner casing), $\alpha$-heat transfer coefficient, $T$-steam temperature, $p$-steam pressure. 


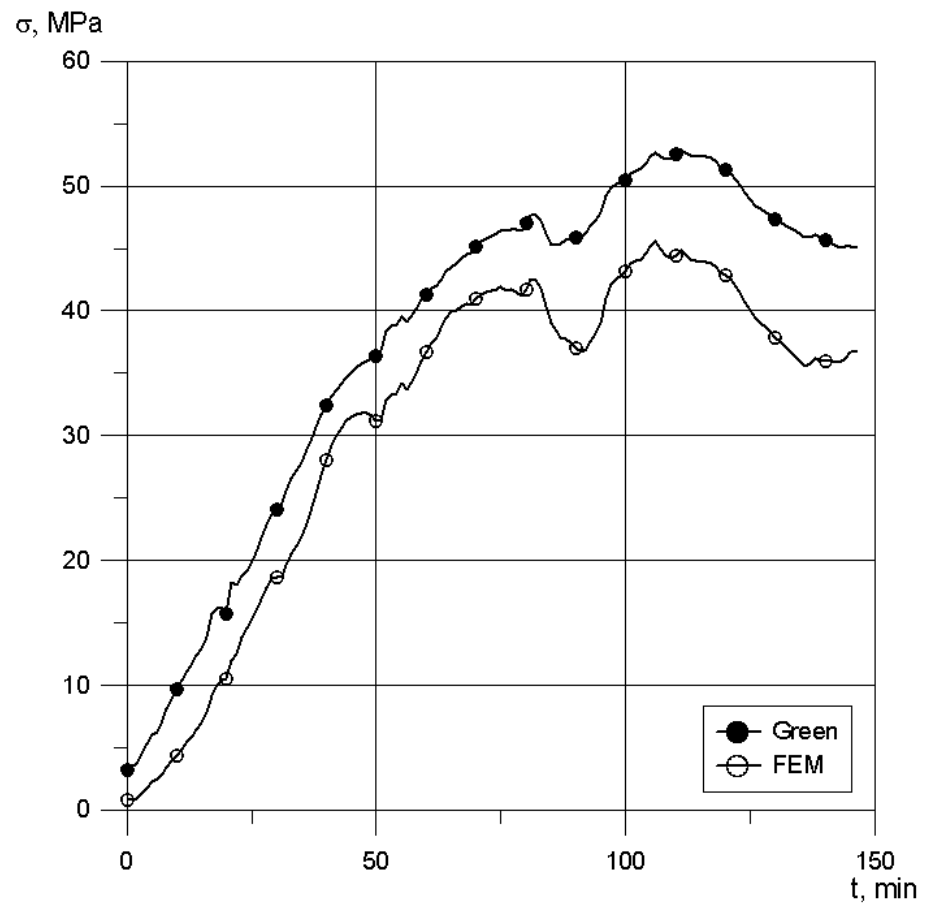

Figure 14. History of changes in stresses in the inner casing during the hot start-up.

\subsection{Turbine Cut-Off Valve}

The second analysed element was the turbine cut-off valve. The place of the occurrence of the highest effective stresses was selected as the valve critical area. The area was localised based on the results of the valve stress-state simulation during a start-up from the cold state. The finite element method in ANSYS was selected again. The hex-dominant mesh type with 63,640 elements was used. The calculations were performed in two stages: the thermal and the structural analyses with the same boundary condition types as for the inner casing. Figure 15 presents the change in steam parameters during this start-up. Figure 16 illustrates the distribution of effective stresses at the moment that their maximum values appear.

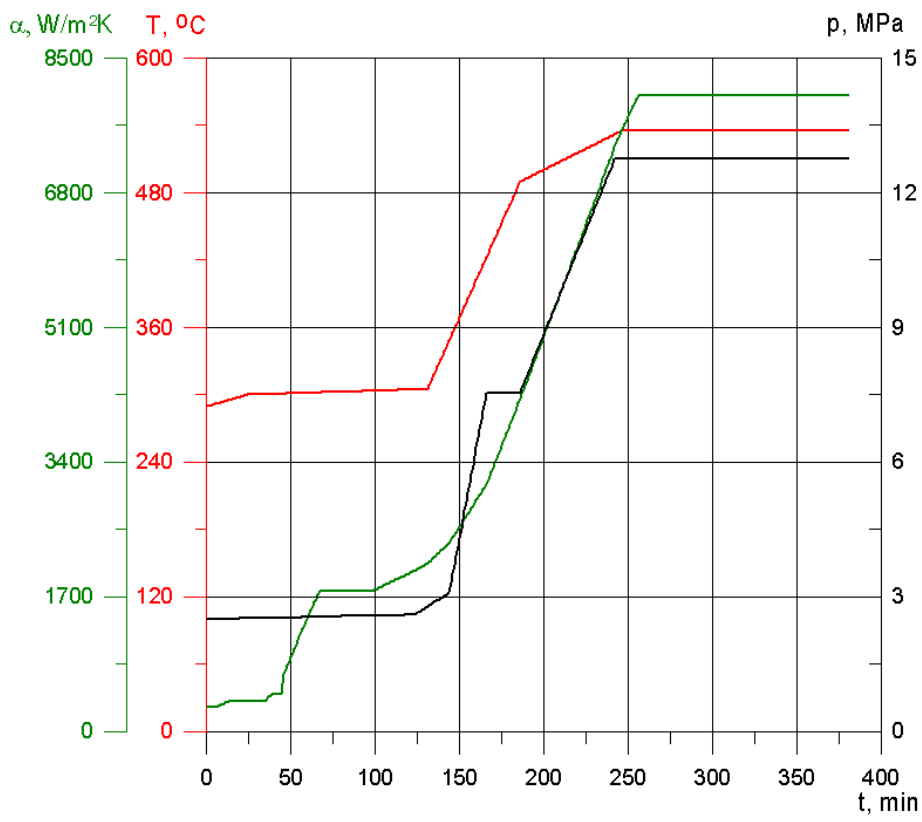

Figure 15. Increment in steam parameters during the cold start-up (data for turbine cut-off valve), $\alpha$-heat transfer coefficient, $T$-steam temperature, $p$-steam pressure. 

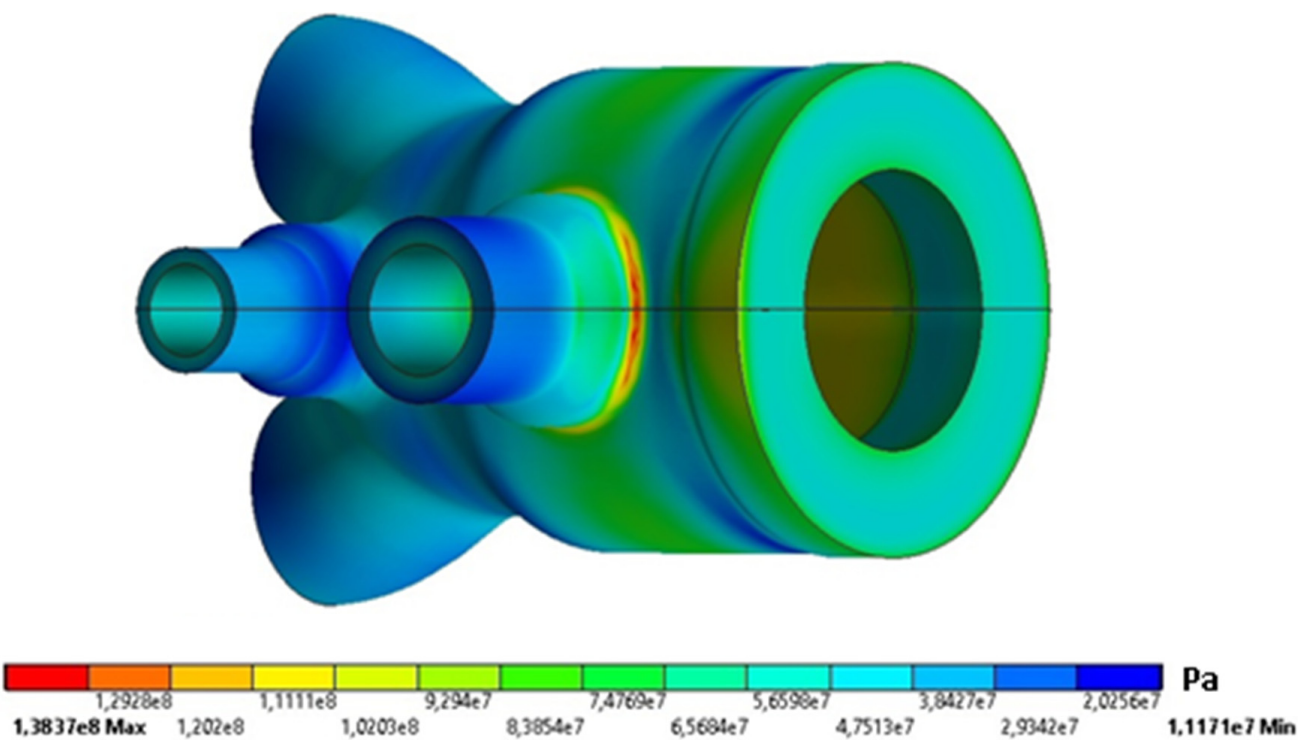

Figure 16. Distribution of stresses in the turbine cut-off valve during the cold start-up.

The cut-off valve monitored area selected based on the results of the described analysis is presented in Figure 17.

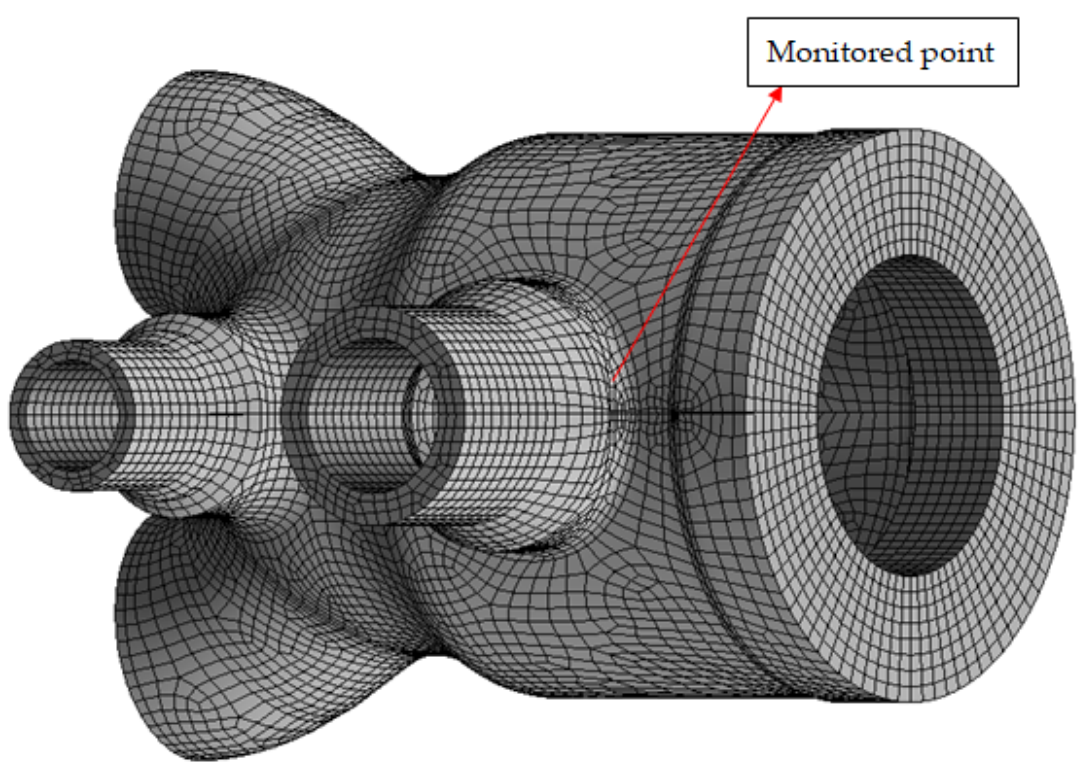

Figure 17. Monitored area in the turbine cut-off valve.

The change in the heat transfer coefficient in the monitored area of the valve calculated using the relations given in Section 3 is relatively big and exceeds $8000 \mathrm{~W} / \mathrm{m}^{2} \mathrm{~K}$. Due to such a big increment, it is necessary to divide the start-up into two intervals depending on the values of the coefficients:

- Interval I: $\alpha \leq 2000 \mathrm{~W} / \mathrm{m}^{2} \mathrm{~K}$,

- Interval II: $\alpha>2000 \mathrm{~W} / \mathrm{m}^{2} \mathrm{~K}$.

Influence functions are assigned to each interval (both for temperature and stresses), which are determined using the finite element method at constant values of the heat transfer coefficient. The relations are determined at $\alpha_{\operatorname{modI}}=942 \mathrm{~W} / \mathrm{m}^{2} \mathrm{~K}$ and $\alpha_{\operatorname{modII}}=2986 \mathrm{~W} / \mathrm{m}^{2} \mathrm{~K}$ for Interval I and Interval II, respectively.

Figure 18 presents the metal temperature influence functions due to a unit increment in temperature. 


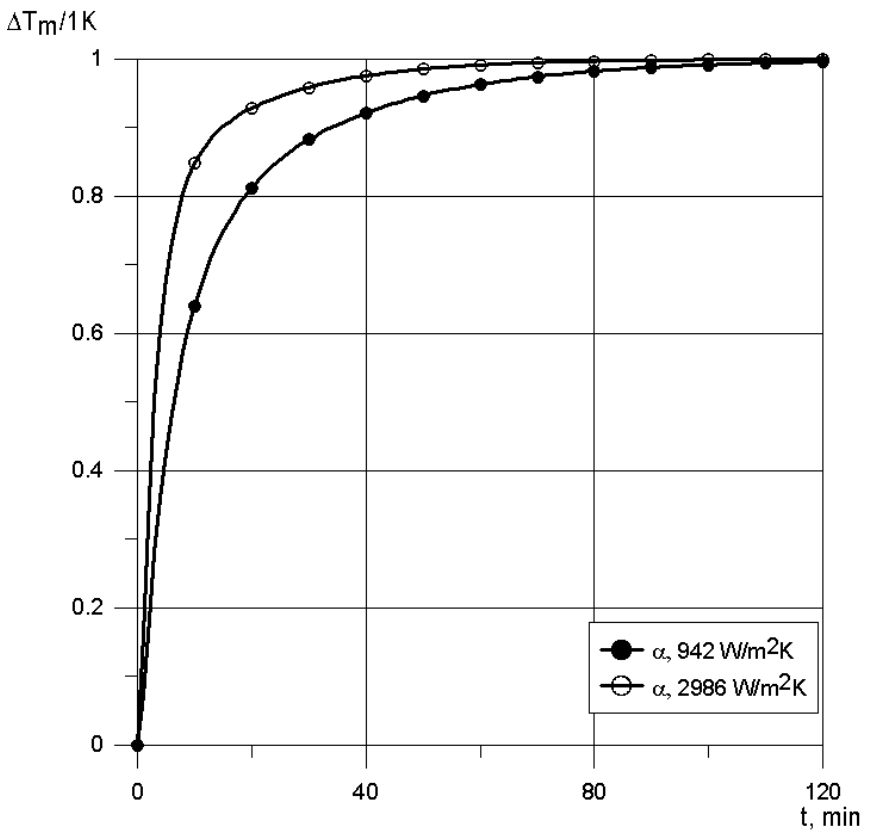

Figure 18. Influence function for the metal temperature in the cut-off valve.

Figures 19 and 20 present Green's functions for the monitored point in the valve for different stress components (normal and tangential, respectively) determined for heat transfer coefficients $\alpha_{\text {modI }}$ and $\alpha_{\text {modII }}$.

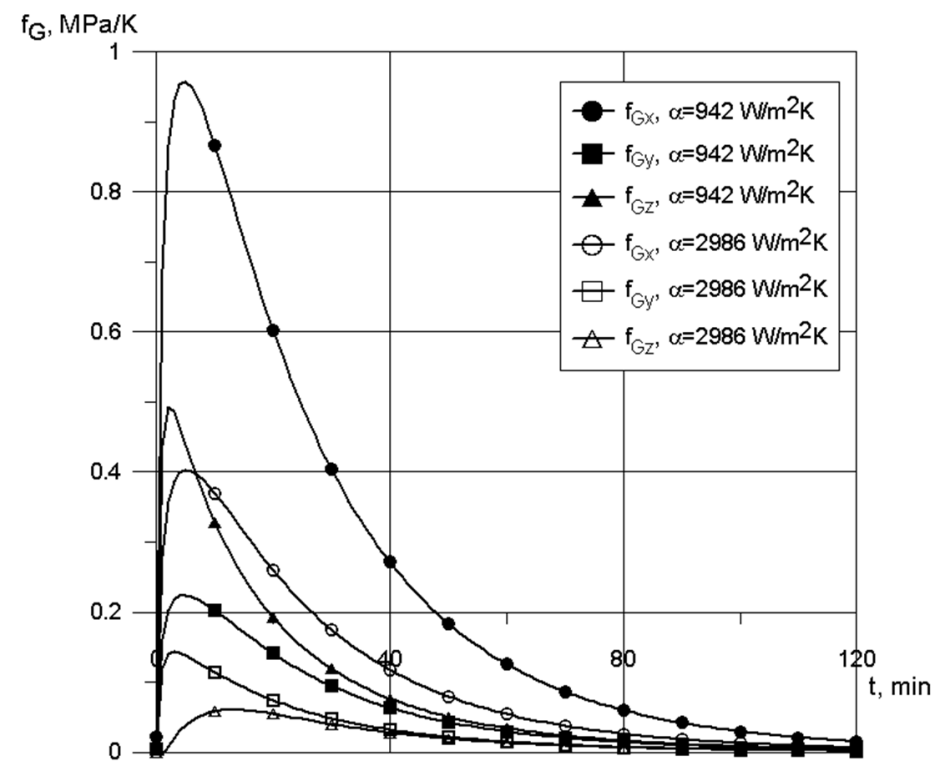

Figure 19. Green's functions for the stress normal components in the cut-off valve. 


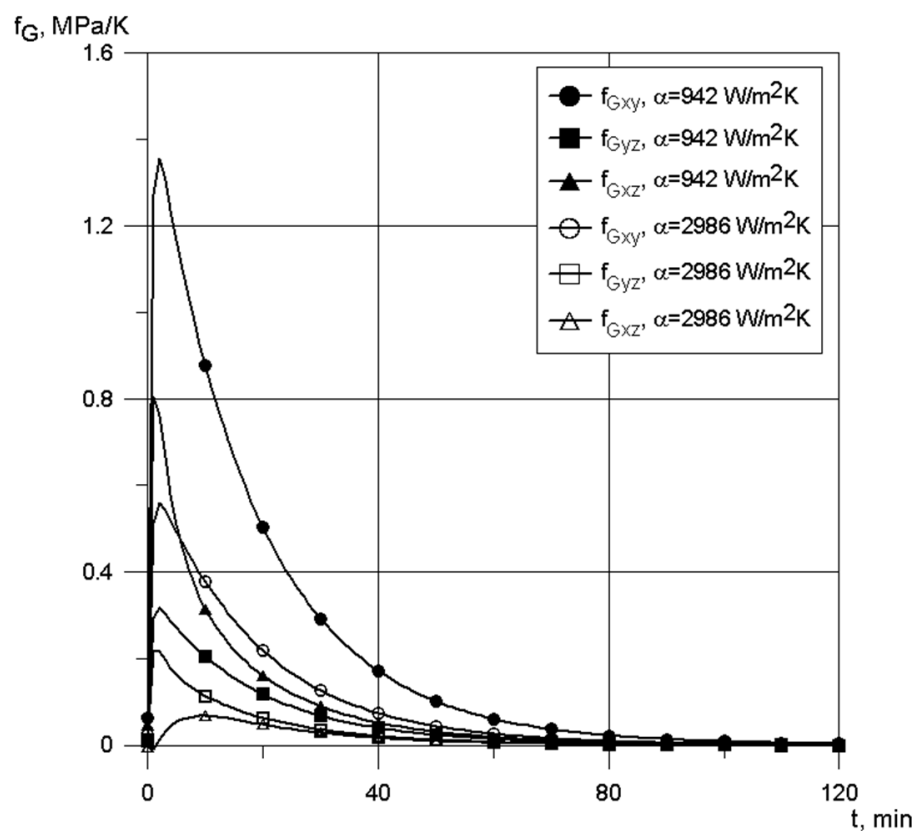

Figure 20. Green's functions for the stress tangential components in the cut-off valve.

Based on the comparison of thermal stresses obtained using the finite element method and the algorithm using Green's functions, constant correction factors were selected for the two intervals under consideration:

- Interval I: $k_{I}=942$

- Interval II: $k_{I I}=2986$

Like the inner casing, the turbine cut-off valve is a pressure component. Therefore, relations were determined for the selected area between steam pressure and stresses arising due to the pressure impact using Equation (13). The coefficients for individual components take the following values (for pressure given in $\mathrm{MPa}$ ):

$$
\begin{gathered}
a_{x}=3.031, b_{x}=0 \\
a_{y}=0.794, b_{y}=0 \\
a_{z}=3.340, b_{z}=0 \\
a_{x y}=1.247, b_{x y}=0 \\
a_{y z}=0.853, b_{y z}=0 \\
a_{x z}=-0.248, b_{x z}=0
\end{gathered}
$$

Effective stresses were found using Equation (15). The histories of stresses obtained for the three start-up kinds (cold, warm, and hot) were compared to the results obtained by means of FEM calculations. Figure 21 presents a comparison drawn for the cold start-up realised according to the characteristic shown in Figure 15. 


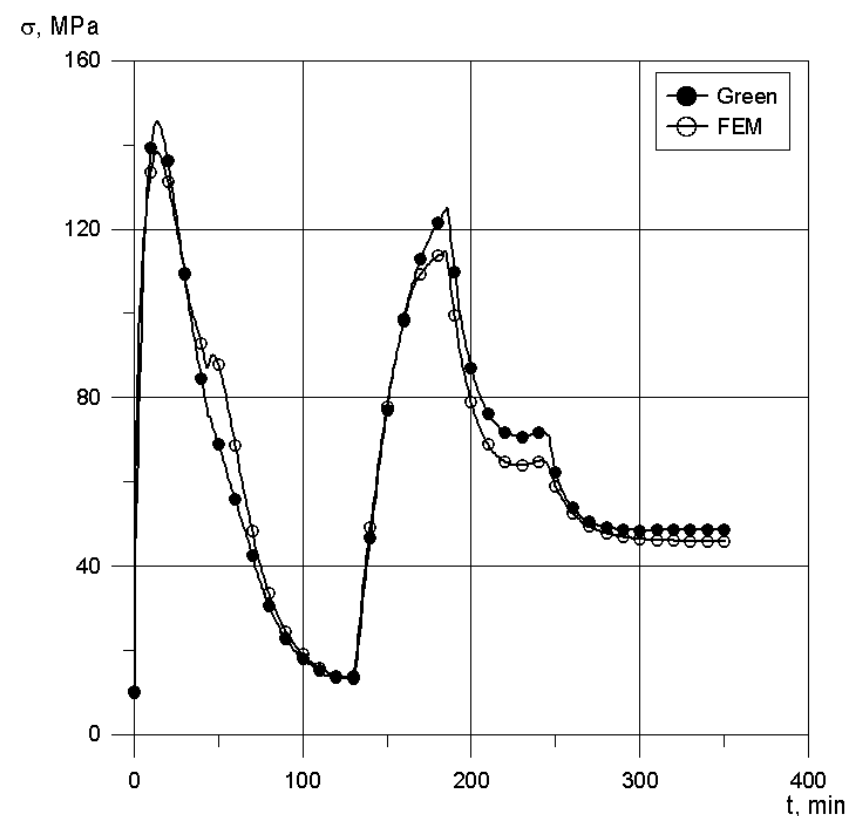

Figure 21. History of effective stresses in the turbine cut-off valve during the cold start-up.

The next case in the analysis was the start-up from the warm state. The change in steam parameters is presented in Figure 22. The histories of effective stresses calculated using Green's functions and the FEM are compared in Figure 23.

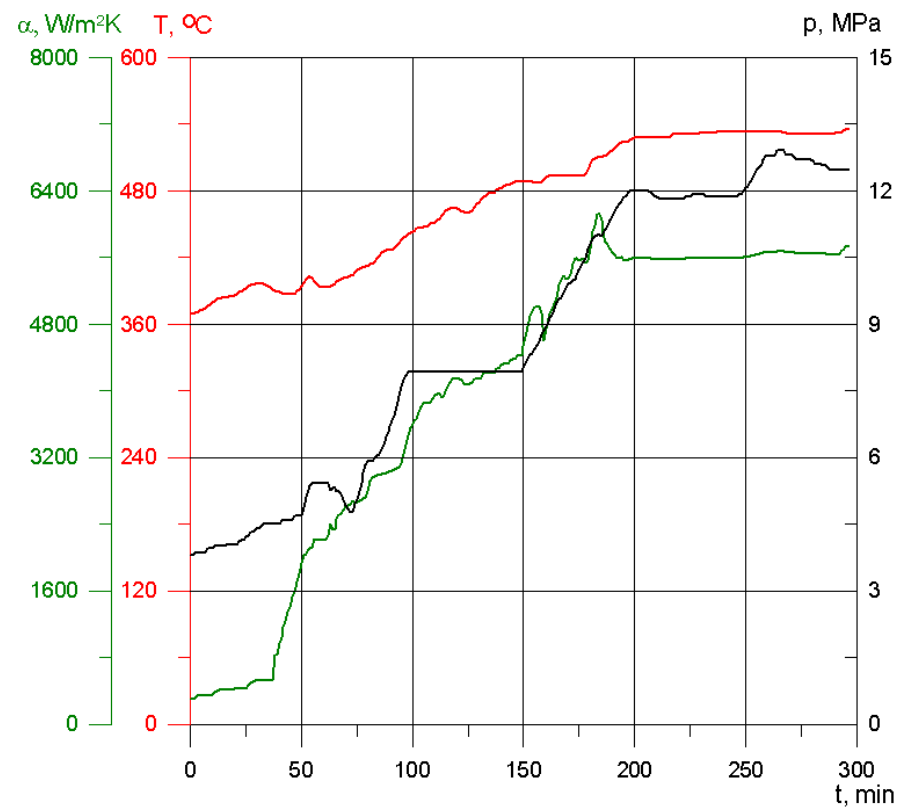

Figure 22. Change in steam parameters during the warm start-up (data for turbine cut-off valve), $\alpha$-heat transfer coefficient, $T$-steam temperature, $p$-steam pressure. 
$\sigma, \mathrm{MPa}$

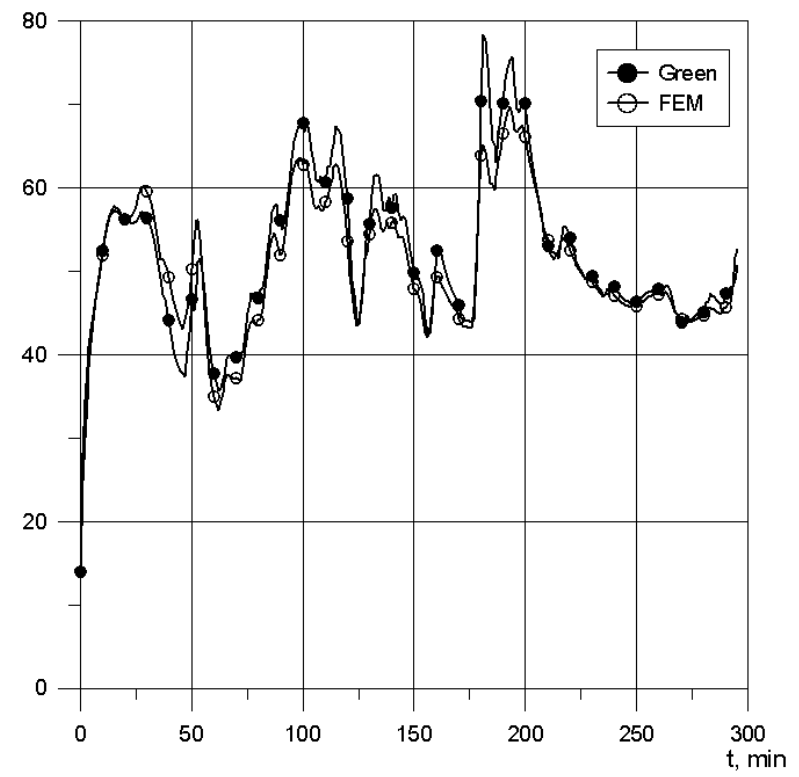

Figure 23. History of stresses in the turbine cut-off valve during the warm start-up.

Similar calculations were performed for the start-up from the hot state. Figure 24 presents the change in steam parameters during the heating process. The results of the calculations of effective stresses are shown in Figure 25.

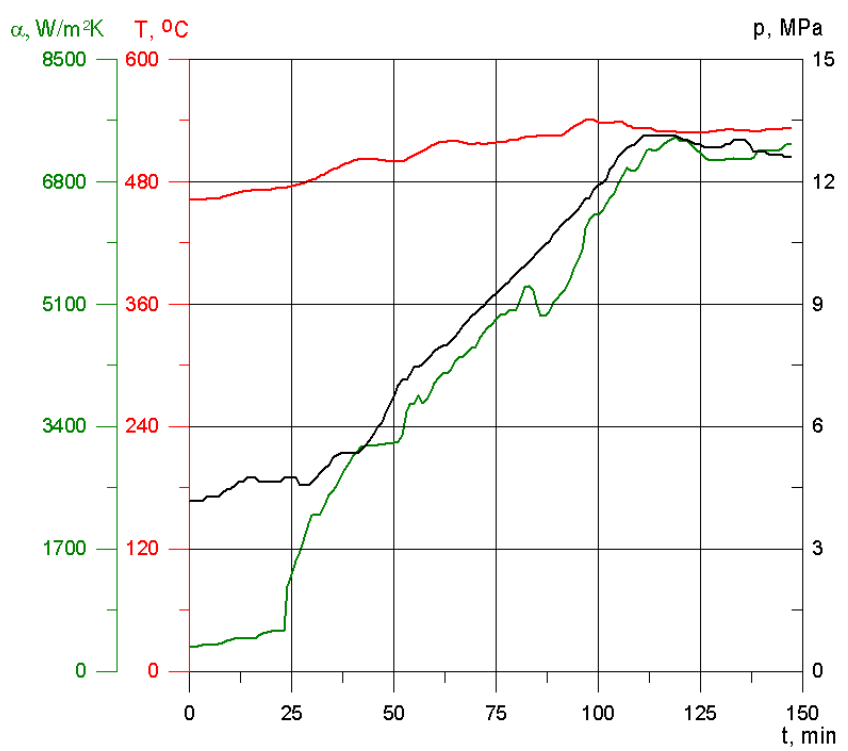

Figure 24. Change in steam parameters during the hot start-up (data for turbine cut-off valve), $\alpha$-heat transfer coefficient, $T$-steam temperature, $p$-steam pressure. 


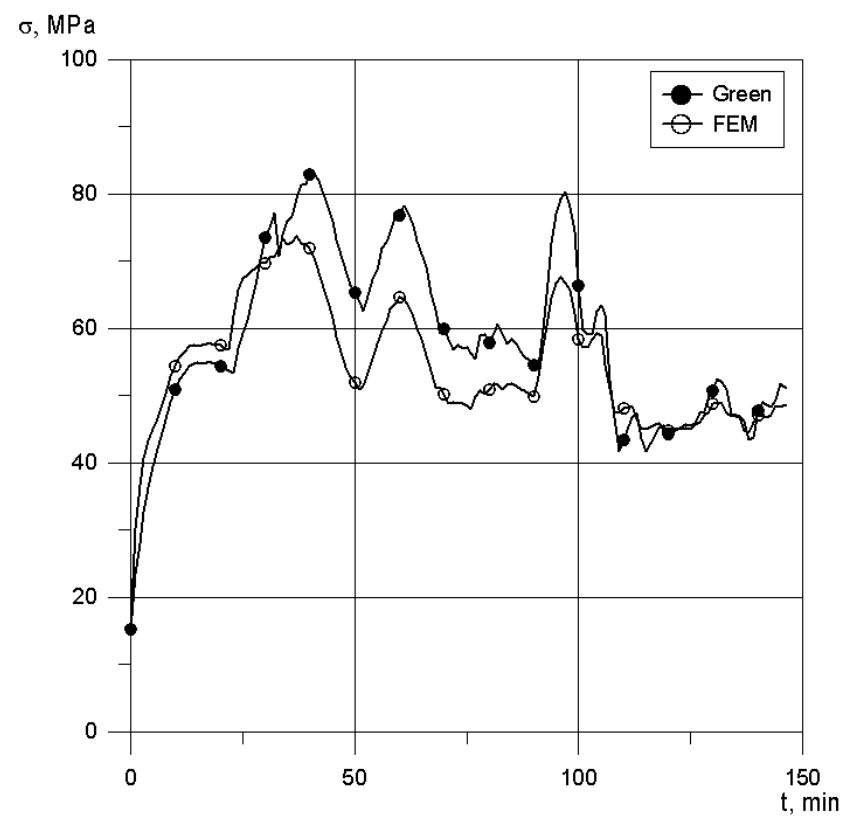

Figure 25. History of stresses in the turbine cut-off valve during the hot start-up.

\section{Controlling the Change in the Turbine Load Depending on the Stress Level}

In real conditions, the start-up of the turbine is strongly related to the start-up of the boiler. Considering that the boiler operation may cause unexpected changes in steam parameters, making them differ from the optimal values, some solutions have to be used that will protect the turbine elements against an excessive increase in stresses. This role is performed by thermal limitation systems, which, based on the algorithms discussed above, model stresses in the turbine critical elements in the on-line mode; if stresses exceed allowable values, they send a signal to the turbine control system and the rate of increments in the power output and rotational speed is reduced.

The reaction to the increasing stress level in the turbine critical element depends on the current location of the point with the following coordinates: element temperature $(T)$ and maximum stress in the element $(\sigma)$ in the chart shown in Figure 26.

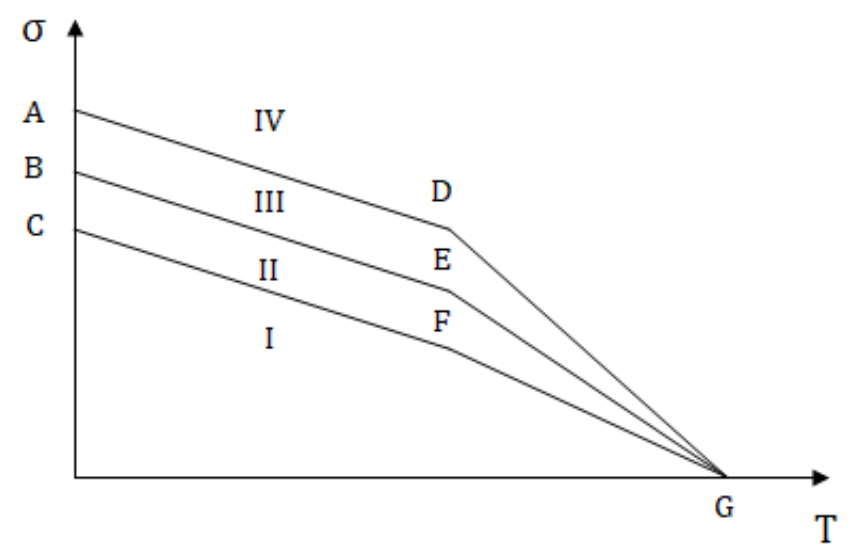

Figure 26. Control areas.

The entire region of possible combinations of the coordinates $(T, \sigma)$ for a given element was divided into four areas (I, II, III, and IV). The areas are limited by segments with characteristic points A, B, C, D, E, F, and G. The coordinates of the points (A, B, C, D, E, F, $\mathrm{D}, \mathrm{E}, \mathrm{F}$, and $\mathrm{G}$ ) are the element characteristic quantities taking account of both the kind of the material and the technical state of the element. 
Area I in Figure 26 means that the current stress state of the element is included within the allowable range. The stress level is below $80 \%$ and there is no need to change the start-up rate. Area II between points B, C, F, G, E, and B means that the element stress state is also in the allowable range. The stresses are between 80 and $100 \%$ of allowable values, but their further increase is undesirable. It is therefore necessary to take measures to reverse the current trend. Area III marks a high level of the material stress state (between 100 and $120 \%$ of allowable stresses) and therefore drastic measures must be taken to reduce the element load. Area IV denotes the unacceptable region of the element operation. The assumptions presented above indicate that the region of stress values to be controlled is Area II. The way of affecting the rate of the increase in the steam temperature is shown in an example. Let us assume that at a given time instant the element temperature is $T_{x}$ (cf. Figure 27).

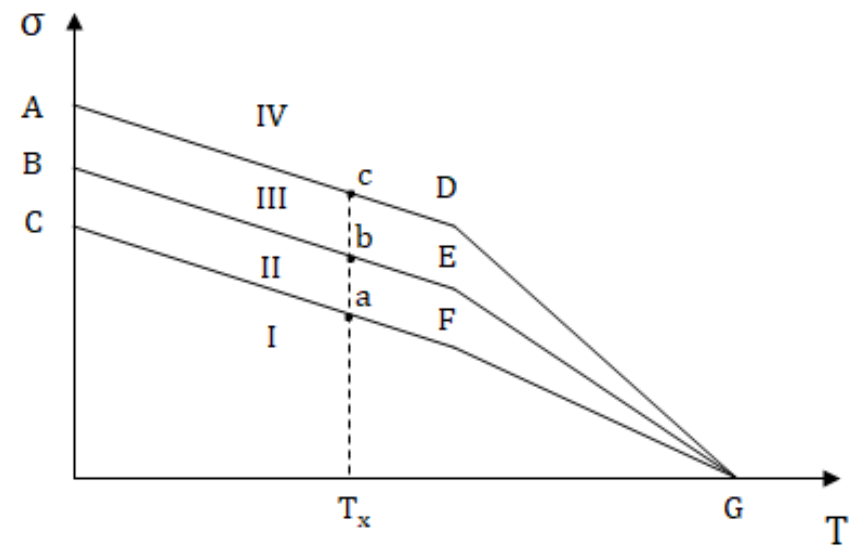

Figure 27. Control range for an element with temperature $T_{x}$.

If under current stress $\sigma$ the element is still in Area I, there is no need to change the start-up rate. If the stress value reaches point " $a$ ", the start-up rate should be reduced in the following manner: assuming that the instantaneous rate of the increase in the steam temperature at the moment that stress reaches the value at point " $a$ " is $100 \%$, the rate is linearly decreased to 0 in the case when stress reaches the value " $b$ " (cf. Figure 28).

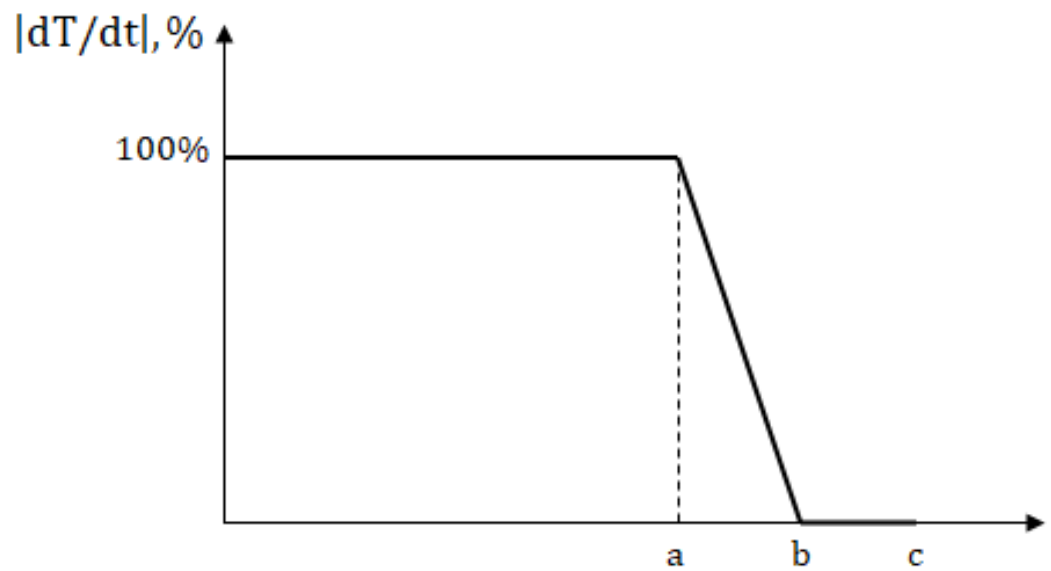

Figure 28. Method of changing steam temperature.

If a further increase in stresses occurs in Area III, the system stops the steam temperature increase: $d T_{p} / d t=0$.

A similar procedure applies to the cooling of steam, i.e., negative values of derivatives $d T_{p} / d t$. For this reason, the derivative in Figure 28 should be treated as an absolute value. 


\section{Conclusions}

The stress level in turbine elements can be monitored on-line using the described algorithms based on Green's functions and Duhamel's integral. By modifying these algorithms to take account of the impact of the variability of heat transfer coefficients on the thermal stress level, it is possible to obtain satisfactory agreement between the stress calculation results and the results obtained using the finite element method. It is particularly important for elements for which the heat transfer coefficient values change during the heating process by several orders of magnitude. For the inner casing, the range of changes in the heat transfer coefficient during start-up is $10-70 \mathrm{~W} / \mathrm{m}^{2} \mathrm{~K}$ on the monitored point and $10-260 \mathrm{~W} / \mathrm{m}^{2} \mathrm{~K}$ on the casing outer surface. For the cut-off valve, the range of changes is much wider and amounts to $10-8000 \mathrm{~W} / \mathrm{m}^{2} \mathrm{~K}$.

In the examples of stress modelling presented in this paper for selected pressure components of the turbine, i.e., the inner casing and the valve, the maximum relative error in stress determination using the two methods, i.e., the finite element method and the described algorithm for the analysed start-ups of the turbine, totalled a few percent. The greatest effective stresses occur during start-ups from cold state and reach values of $90 \mathrm{MPa}$ for the turbine inner casing and $150 \mathrm{MPa}$ for the turbine cut-off valve. When the initial temperature of element is higher (during warm or hot start-ups) the maximum stresses drop to approximately $50 \mathrm{MPa}$ in the casing and $80 \mathrm{MPa}$ in the valve.

The introduction of a stress control system based on the above-described calculation algorithm makes it possible to improve the power unit operating flexibility and facilitates operation control while ensuring the safety of individual elements. The presented simple load-control algorithm depending on the current stress level enables maintaining operational safety. Additionally, the acquired data can be used to calculate fatigue-related life consumption as well as to predict the residual lifetime of individual elements and enable rational planning of the diagnostic and repair management.

Author Contributions: Conceptualisation, A.R.; methodology, A.R.; software, M.T. and G.N.; validation, H.Ł. and W.K.; formal analysis, A.R.; investigation, M.T. and W.K.; writing-original draft preparation, M.T.; supervision, A.R. All authors have read and agreed to the published version of the manuscript.

Funding: The presented research was performed within the Silesian University of Technology Rector's Pro-quality grant no: 08/050/RGJ20/0207.

Data Availability Statement: Not applicable.

Conflicts of Interest: The authors declare no conflict of interest.

\section{References}

1. Stoppato, A.; Mirandola, A.; Meneghetti, G.; Lo Casto, E. On the operation strategy of steam power plants working at variable load: Technical and economic issues. Energy 2012, 37, 228-236. [CrossRef]

2. Rusin, A.; Bieniek, M.; Lipka, M. Assessment of the rise in the turbine operational risk due to increased cyclicity of power unit operation. Energy 2016, 96, 394-403. [CrossRef]

3. Łukowicz, H.; Rusin, A. The impact of the control method of cyclic operation on the power unit efficiency and life. Energy 2018, 150, 565-574. [CrossRef]

4. Tomala, M.; Rusin, A.; Wojaczek, A. Risk-Based Planning of Diagnostic Testing of Turbines Operating with Increased Flexibility. Energies 2020, 13, 3464. [CrossRef]

5. Lausterer, G.K. On-line thermal stress monitoring using mathematical models. Control. Eng. Pract. 1997, 5, 85-90. [CrossRef]

6. Taler, J.; Węglowski, B.; Zima, W.; Grądziel, S.; Zborowski, M. Analysis of Thermal Stresses in a Boiler Drum During Start-up. J. Press. Vessel. Technol. 1999, 121, 84-93. [CrossRef]

7. Taler, J.; Dzierwa, P.; Taler, D.; Harchut, P. Optimization of the boiler start-up taking into account thermal stresses. Energy 2015, 92, 160-170. [CrossRef]

8. Nowak, G.; Rusin, A.; Łukowicz, H.; Tomala, M. Improving the power unit operation flexibility by the turbine start-up optimization. Energy 2020, 198, 117303. [CrossRef]

9. Dettori, S.; Maddaloni, A.; Colla, V.; Toscanelli, O.; Buciarelli, F.; Signorini, A.; Checcacci, D. Nonlinear model predictive control strategy for steam turbine rotor stress. Energy Procedia 2019, 158, 5653-5658. [CrossRef] 
10. Song, G.; Kim, B.; Chang, S. Fatigue life evaluation for turbine rotor using Green's function. Procedia Eng. 2011, $10,2292-2297$. [CrossRef]

11. Mukhopadhyay, N.K.; Dutta, B.K.; Kushwaha, H.S. On-line fatigue-creep monitoring system for high-temperature components of power plants. Int. J. Fatigue 2001, 23, 549-560. [CrossRef]

12. Rusin, A.; Nowak, G.; Lipka, M. Practical algorithms for online thermal stress calculations and heating process control. J. Therm. Stresses 2014, 37, 1286-1301. [CrossRef]

13. Nowak, G.; Rusin, A. Using the artificial neural network to control the steam turbine heating process. Appl. Therm. Eng. 2016, 108, 204-210. [CrossRef]

14. Ko, H.O.; Jhung, M.J.; Choi, J.B. Development of Green's function approach considering temperature-dependent material properties and its application. Nucl. Eng. Technol. 2014, 47, 101-108. [CrossRef]

15. Zhang, H.L.; Liu, S.; Xie, D.; Xiong, Y.; Yu, Y.; Zhou, Y.; Guo, R. Online fatigue-monitoring models with consideration of temperature dependent properties and varying heat transfer coefficients. Sci. Technol. Nucl. Install. 2013, 2013. [CrossRef]

16. Rouse, J.; Hyde, C. A comparison of simple methods to incorporate material temperature dependency in the Green's function method for estimating transient thermal stresses in thick-walled power plant components. Materials 2016, 9, 26. [CrossRef]

17. Koo, G.H.; Kwon, J.J.; Kim, W. Green's function method with consideration of temperature dependent material properties for fatigue monitoring of nuclear power plants. Int. J. Press. Pip. 2009, 86, 187-195. [CrossRef]

18. Łukowicz, H. Analysis Problems in Flow Calculations of Steam Turbines Applied in Diagnostics and Design. ZN Politech. Ślaskiej S. Energetyka 2005, 143, 1-2.

19. Rusin, A.; Łukowicz, H.; Kosman, W. Transient Temperature and Thermal Stresses in Turbine Components. In Encyclopedia of Thermal Stresses; Springer Science: Dordrecht, The Netherland, 2015.

20. Chmielniak, T.; Kosman, G.; Łukowicz, H. Analysis of Mean Convective Heat Transfer Coefficients in Steam Turbine Valves. Trans. Inst. Fluid Flow Mach. 1994, 87, 25-40.

21. Dirker, J.; Meyer, J.P. Convective Heat Transfer Coefficients in Concentric Annuli. Heat Transf. Eng. 2005, 26, 38-44. [CrossRef] 